\title{
Educação e desenvolvimento da pessoa no personalismo de Emmanuel Mounier
}

\author{
Josi Mara Nolli ${ }^{1}$
}

\section{Resumo:}

Este artigo é parte do estudo de mestrado que investigou a concepção de educação e pessoa à luz do personalismo de Emmanuel Mounier. Para o personalismo mounieriano a pessoa não nasce perfeita, ou seja, pronta. O homem é chamado a "amadurecer livremente" como pessoa. Isso envolve dois aspectos fundamentais para o seu desenvolvimento - a liberdade, que the confere a possibilidade de escolha, e o protagonismo, que o coloca como principal responsável por seu desenvolvimento. O desenvolvimento da pessoa, em Mounier, é um processo que depende, sobretudo, da própria pessoa. Tal protagonismo evidencia que a educação, para o personalismo é, na verdade, autoeducação.

Palavras-chave: Pessoa. Educação. Personalismo.

\begin{abstract}
:
This article is part of the master's study that investigated the concept of education and person in the light of Emmanuel Mounier's personalism. For Mounierian personalism, the person is not born perfect, that is, ready. Man is called to "mature freely" as a person. This involves two fundamental aspects for its development - freedom, which gives it the possibility of choice, and protagonism, which places it as the main responsible for its development. The development of the person, in Mounier, is a process that depends, above all, on the person himself. Such protagonism shows that education, for personalism, is, in fact, self-education.
\end{abstract}

Keywords: Person. Education. Personalism.

\section{Introdução}

O personalismo de Emmanuel Mounier esforça-se por resgatar a pessoa da reificação, num cenário marcado pela crise econômica de 1929 que atingiu a Europa e outras partes do mundo e pela Segunda Guerra

\footnotetext{
${ }^{1}$ Mestre em Educação pela Universidade Estadual de Campinas (Unicamp). Graduada em Comunicação Social, jornalismo pela Pontifícia Universidade Católica de Campinas (PUC).
} 
Mundial. Nesse contexto, predominam a banalização e a negação da pessoa. A crítica de Mounier é endereçada aos sistemas que não compreendem a pessoa como valor absoluto, em função do qual devem ser pensados todos os fins da organização política.

A questão que se coloca no personalismo mounieriano está na relação entre pessoa e indivíduo. Na perspectiva personalista de Mounier, a pessoa não é o indivíduo, porque esse caracteriza-se pelo egocentrismo e pelo isolamento, atitudes características do individualismo.

O pensamento de Mounier procura dar um novo significado à pessoa, lutando contra a reificação fomentada pelos sistemas político, social e econômico da época. A saída para essa crise, de acordo com Mounier, estava na mudança tanto das estruturas econômicas quanto dos valores sociais. Propunha-se, assim, a superar a dicotomia existente entre o marxismo e o espiritualismo ${ }^{2}$.

Ao lançar as diretrizes básicas da filosofia personalista, Mounier coloca a pessoa como o núcleo central de suas preocupações. A pessoa passa a ser o centro orientador da reflexão e da ação do movimento Esprit. Trata-se, segundo Peixoto (2009), de uma antropologia filosófica que procura compreender o homem como pessoa. Mas essa dimensão antropológica não pretende apenas uma teorização do universo pessoal. A elaboração teórica tem a finalidade de se constituir num instrumento prático de afirmação do caráter absoluto da pessoa, sendo esse absoluto entendido como fim que dá sentido a toda organização política e social, no que se refere aos direitos da pessoa.

Conforme Peixoto (2017, p. 16), a proposta de Mounier consistia na construção de um humanismo em constante confronto com os acontecimentos e crises da época, tendo como característica principal a

\footnotetext{
${ }^{2}$ Mounier endereça sua crítica aos marxistas e aos espiritualistas. Os primeiros, tendo como principal representante Karl Marx, afirmavam que a crise (o pessimismo e a insegurança que tomavam conta da Europa, a banalização e a negação da pessoa) era decorrência da crise econômica e a saída, portanto, seria mudar as estruturas econômicas. Já para os espiritualistas, tratava-se de uma crise de valores, não da economia, mas do homem. Para Mounier, espiritualistas e materialistas participavam do mesmo erro, pois separavam o corpo e a alma, o pensamento e a ação, o homo faber e o homo sapiens (PEIXOTO, 2009, p. 23).
}

Filos. e Educ., Campinas, SP, v.12, n.2, p.1032-1054, maio/ago. 2020 - ISSN 1984-9605 
defesa da dignidade inalienável da pessoa contra todas as formas de opressão e de agressão - políticas, sociais, jurídicas, morais e econômicas -, na busca do pleno desenvolvimento de cada homem como pessoa.

Mounier (1974) não pretende, a rigor, definir a pessoa: para ele, a pessoa não pode ser definida, pois não é objeto; esse pode ser dissecado e examinado, ao passo que a pessoa é, exatamente, aquilo que em cada homem não é passível de ser tratado como objeto. Desse modo, o que se encontra em seus textos é uma caracterização da pessoa, dada por meio de um movimento dialético.

O filósofo compreende a pessoa em dimensões que envolvem aspectos transcendentes, mas sem desconsiderar os elementos sócio-políticoeconômicos, ou seja, trata-se da pessoa situada no mundo e na história, permanecendo no centro de suas reflexões a questão da liberdade.

A pessoa pode, então, escolher seus valores políticos e econômicos tanto quanto os estéticos, éticos, morais etc., num processo e/ou percurso de livre amadurecimento. A educação, compreendida como ato de educar, pode despertá-la para tal movimento.

Despertar pessoas - a finalidade da educação

Porque se educa a criança? Esta pergunta depende doutra: qual é o fim dessa educação? Este não consiste em fazer, mas em despertar pessoas.

Por definição uma pessoa suscita-se por apelos, não se fabrica domesticando. A educação não pode ter como fim, moldar a criança ao conformismo dum meio familiar, social ou estadual $\left[\right.$ estatal $\left.^{3}\right]$, nem se restringirá a adaptá-la à função ou papel que lhe caberá desempenhar quando adulto (MOUNIER, 1974, p. 200; grifos do autor).

\footnotetext{
${ }^{3}$ No texto original Le personnalisme (1949, p. 129) a palavra é étatique, cuja tradução é "estatal", não "estadual".
} 
Mounier (1974) rejeita as ideias de "fazer", "moldar", "fabricar" como fins da educação. É num contexto de combate ao individualismo que essa rejeição se dá. Para o filósofo, tais noções implicam limite - o que a forma e/ou a fôrma comportar(em) -, assim como a noção de "coisa feita", ou seja, que recebeu forma, e, ainda, a ausência de participação na formação do que é formado. Tais noções remetem ainda à ideia de formalismo e de autoritarismo, em que a pessoa não é considerada no movimento de seu próprio desenvolvimento, por ser tratada como objeto, como coisa (res), portanto, não sendo respeitada em sua liberdade.

O filósofo (1974) afirma que a educação tem por fim “despertar pessoas". Para Mounier, o homem está adormecido, ou seja, acomodado, inerte em seus confortos, fadigas, prazeres etc., dominado pelo individualismo, em suma, alienado, indiferente a tudo e a todos. Dessa perspectiva, a educação teria por fim "acordar" o homem para ser e viver como pessoa. Isso implica, na visão de Mounier, "tomada de consciência" recusa dos mecanismos de reificação do homem e, ao mesmo tempo, um apelo às ações que contribuam para as mudanças de tais mecanismos. É sair da indiferença, do que se pode chamar de consciência sonolenta - a consciência que torna o homem indiferente, alienado.

Conforme Peixoto (2009, p. 66), Mounier atribui à educação a função de alertar as pessoas para a gravidade da crise da civilização burguesa ocidental, que transformou a razão numa razão utilitarista. Não se trata de formar o homem, no sentido de fazê-lo, mas de despertá-lo da alienação e da indiferença, a partir daquela tomada de consciência e de uma atitude de engajamento e afrontamento, no combate a essas estruturas. Disso resulta o chamado para a necessidade de se refazer a Renascença, ou seja, recolocar o homem como pessoa (e não como indivíduo), como centro de todas as estruturas políticas, econômicas e sociais. Esse despertar significa desenvolver nos seres humanos, submetidos ao processo educativo, enquanto contingência histórica em permanente formação e devir, a consciência do respeito e da valorização de si e do outro como pessoa, a partir da singularidade de toda dimensão pessoal. 
A expressão "despertar pessoas" remete à ideia de suscitar a pessoa no homem, o que pressupõe pensar que a pessoa esteja de alguma forma adormecida. A educação a despertaria provocando no homem o movimento de personalização - aquele que o homem realiza para assumir sua condição de pessoa, podendo ser compreendida como um momento de se criar condições para provocar o despertar da pessoa.

Que condições ou situações poderiam ser essas? Na visão do personalismo, pode ser o diálogo, numa perspectiva de partilha de experiências e aprendizagens com outras pessoas, tendo em vista Mounier afirmar que a pessoa não se caracteriza pelo isolamento. Mounier (1974, p. 63) afirma que "a experiência primitiva da pessoa é a experiência da segunda pessoa", o que significa que as primeiras identificações da criança de si em relação ao mundo que a cerca e em relação à tomada de conhecimento se dá por via experimental do outro. A educação pode considerar, então, as relações de convivência, fomentando o diálogo frutífero e fecundo entre a pessoa e o outro. A pessoa pode se desenvolver em uma perspectiva de partilha de experiências e aprendizagem de si e em relação aos outros, pela descoberta si através dos outros.

Pode-se considerar também a criação de condições para que a pessoa mesma possa lidar com possíveis contrariedades da vida e tenha capacidade, por exemplo, de transformá-las, dando a elas novos significados. O filósofo mesmo afirma que ao Estado cabe assegurar, por exemplo, condições para o exercício da liberdade, o qual deve começar na sua relação com a própria escola - garantir condições para que se tenha escola pública, livre, que seja expressão da vontade da pessoa, da família, dos educadores etc., ou seja, uma escola pluralista.

A educação a que se refere Mounier não é, exclusivamente, educação escolar. Ao tratar da educação da pessoa, o filósofo afirma que "a formação da pessoa no homem e do homem, nas exigências individuais e coletivas do universo pessoal, começa no nascimento" (MOUNIER, 1974, p. 200). Começa, portanto, na família, que é a instância do nascimento da pessoa, 
instância em que a pessoa experimenta os primeiros conflitos, as primeiras expectativas e, do mesmo modo, as primeiras lições.

Sendo assim, a educação de que trata Mounier não diz respeito apenas à escolarização ou à educação formal, mas envolve o ato de educar em sua acepção mais ampla. Isso não significa que Mounier desconsidere o papel da escola; pelo contrário, para ele a família e a escola são as instituições educativas por excelência, isto é, o papel fundamental tanto da família quanto da escola é o de educar. Tal educação começa na família e por ela deve ser mantida, sendo, ao mesmo tempo, reforçada e ampliada pela escola.

\section{O pleno desenvolvimento da pessoa}

A compreensão dos significados do pleno desenvolvimento da pessoa, em Emmanuel Mounier, se dá à medida que se compreende como a pessoa está caracterizada no personalismo.

5. ${ }^{\circ}$ - A esse movimento [o da existência humana] o homem é livremente chamado. A liberdade é constitutiva da existência criada. Deus teria podido criar num momento uma criatura tão perfeita quanto o pudesse ser. Preferiu que fosse o homem o chamado a amadurecer livremente a humanidade e os efeitos da vida divina. O direito de pecar, ou seja, de recusar o seu destino, é essencial ao pleno uso da liberdade. Longe de ser um escândalo, antes seria a sua ausência que alienaria o homem (MOUNIER, 1974, p. 25).

Para Mounier (1974, p. 26), "cada pessoa é criada à imagem de Deus”. Tal pensamento tem suas bases no cristianismo ${ }^{4}$. Deus, na concepção cristã,

\footnotetext{
4 "O imago Dei (a ideia de que o homem foi feito à imagem e semelhança de Deus) constituiu-se na mais significativa contribuição para a guinada antropocêntrica na modernidade, pois, mesmo que o lugar de Deus tenha, mais tarde, sido ocupado pela razão
} 
é um Ser perfeito. Sendo a pessoa criada à Sua imagem, poder-se-ia concluir que a criatura também é perfeita, assim como o Criador. Mounier afirma que "Deus teria podido criar num momento uma criatura tão perfeita quanto o pudesse ser", ou seja, uma criatura acabada, pronta, sem nada que nela fosse preciso ser acrescentado ou completado. Contudo, não o fez; o filósofo usa a expressão "teria podido", significando uma possibilidade que não se cumpriu. A criatura, então, não é perfeita, ou seja, não está totalmente acabada.

Se o filósofo diz que tal criatura poderia ser perfeita, mas não é, não está pronta, é porque a liberdade é constitutiva dessa existência criada. Nesse sentido, ao mesmo tempo que expõe uma visão cristã de pessoa - a que é feita à imagem de Deus -, traz para o centro de suas reflexões as possibilidades que a liberdade dá à pessoa, dentre elas, a de amadurecer livremente. E se há tal possibilidade é porque a pessoa está, de certa forma, por se completar.

A liberdade, para Mounier (1974, p. 110), é a afirmação da pessoa, contudo não é algo dado, mas uma conquista. A palavra "conquista" pode significar um conseguimento, um movimento que supõe busca, daí se somar a ela o sentido de avanço - se se busca e se se conquista, o movimento é de "ir em frente". Para alcançá-la o homem precisa se pôr a caminho, o que o coloca também responsável pela liberdade, pois só ele pode buscá-la. Mounier afirma que o Estado oferece condições para o exercício da liberdade, o que pressupõe que para exercê-la o homem precisa tê-la conquistado. Essa responsabilidade é posta de modo explícito pelo autor: é a pessoa que se faz livre. A palavra "faz" afirma a ideia de que a liberdade é uma experiência. Tal responsabilidade cresce ainda porque a liberdade é fruto primeiro de uma escolha. Primeiro a pessoa escolhe ser livre. Essa escolha pode significar a escolha de se libertar de tudo o que é obstáculo ao exercício da liberdade - o individualismo, o conformismo, a indiferença, por exemplo. E só depois se faz livre, ou seja, faz a experiência da liberdade. A conquista da liberdade passa pela experiência da própria liberdade. centralidade no mundo da vida" (BRAGATO, 2010, p. 83 apud PEIXOTO, 2017, p. 21). 
Amadurecer, nesse contexto, tem a ver com o desenvolvimento da pessoa, pois significa um tornar melhor, crescer, aperfeiçoar-se. Tem a ver, portanto, com o seu pleno desenvolvimento. Tendo em vista que a pessoa não foi criada de modo a estar acabada e pronta, é nesse processo de amadurecer que pode se dar a plenitude de seu desenvolvimento. A pessoa, no personalismo, é chamada a amadurecer, ou seja, a se desenvolver. Fica pressuposto, então, um esforço de sua parte, o que significa que o pleno desenvolvimento é um processo que depende da pessoa. Cabe, então, à própria pessoa alcançar a plenitude, na medida em que é criatura incompleta, chamada a amadurecer. Nisso consiste a plenitude do desenvolvimento - na completude que se dá pelo amadurecer. Amadurecer, portanto, é o processo de se completar, de se realizar.

Contudo, trata-se de um amadurecer livremente, ou seja, nesse processo de desenvolvimento está presente a liberdade. O filósofo enfatiza, por exemplo, o direito da pessoa de pecar, de recusar seu destino - o de amadurecer, em si própria, a humanidade. A pessoa, então, pode escolher pecar ou não, e isso não se configura como escândalo, segundo Mounier; antes, é essencial ao pleno uso da liberdade e, por conseguinte, ao processo de amadurecer da pessoa. Assim, o pleno desenvolvimento da pessoa é um processo que envolve a escolha, visto que a pessoa é chamada a amadurecer livremente.

Para o filósofo, a ausência do direito de pecar, ou seja, de recusar o seu destino humano que é amadurecer, "alienaria o homem". Mounier (1974, p. 109) sustenta que o homem sem liberdade não passa de um joguete, um objeto nas mãos dos outros, querendo dizer da pessoa como coisa e remetendo, certamente, à noção de "fazer": a pessoa seria coisa pronta, feita, que não participa do processo de desenvolvimento. Tem-se aí, novamente, a ideia de alienação, a qual, no contexto da liberdade, pode pressupor a falta do direito de a pessoa aceitar ou recusar, por exemplo, o destino de amadurecer como ser humano, de realizar suas escolhas. $\mathrm{Na}$ medida em que é livre para escolher, a pessoa, segundo Mounier, não se reduz a objeto. 
Se a liberdade envolve escolhas, ela implica responsabilidade. Ao mesmo tempo em que a pessoa é livre para recusar, é também responsável por essas escolhas. O homem livre é o homem responsável, afirma Mounier. Severino (1974, p. 71-72) comenta que essa liberdade é conquista, mas implica também adesão numa luta onde cada passo se consolida por escolhas conscientes e engajadas, o que significa que ela deve ser sempre reconquistada.

Com tais reflexões, o filósofo responde à pergunta: como o homem amadurece, ou seja, se desenvolve como pessoa? A resposta mais evidente nos parece: à medida que escolhe. Assim, na visão de Mounier, a pessoa não é uma criação perfeita, de modo que nada nela precise ser completado; antes, é o que o filósofo chama de "permanência aberta", estruturando-se como uma essência, mas não de forma fixa e imutável, e sim como "fonte viva do ser", e também como criação, construída pela ação responsável, tornando-se naquilo que ela mesma se faz (SILVA, 2015, p. 85).

Acrescenta-se a essas interpretações a ideia de protagonismo, entendido como o ato de assumir função ou papel principal em determinado processo ou atividade. Se a pessoa pode amadurecer livremente e isso envolve suas escolhas, fica implícito que a pessoa é protagonista, ou seja, é a principal responsável por seu pleno desenvolvimento. Significa ainda que a pessoa é ativa nesse processo, tendo em vista que dele participa na liberdade, escolhendo, decidindo.

Outra característica da pessoa que comparece em Mounier é que, na perspectiva desse filósofo, a pessoa é o comum:

Ser pessoal, singularizar-se, eis uma sinonímia corrente na nossa linguagem. Quando falamos de uma personalidade vincada, dizemos: um original. A opinião culta na nossa época faz mesmo, muitas vezes, da diferença o valor dominante da pessoa. Dizemo-la ameaçada quando os costumes e vestuários se uniformizam por toda a parte. Na verdade, é certo que a pessoa é o que nunca se repete, mesmo quando as faces e gestos dos 
homens, caindo sem cessar na generalidade, se copiam desesperadamente à superfície. Mas a procura da originalidade surge sempre como produto secundário, para não dizer subproduto da vida pessoal.

[...] não devemos pensar que a mais alta vida pessoal seja a da excepção, que atinge, sozinha, cumes inacessíveis com as maiores proezas. O personalismo não é uma ética dos "grandes homens", uma aristocracia dum gênero novo que selecione os mais prestigiosos sucessos psicológicos ou espirituais para com eles fazer chefes altivos e solitários da humanidade [...].

Se a pessoa se cumpre na realização de valores infinitamente longe situados é, no entanto, chamada a atingir o extraordinário no próprio centro da vida cotidiana. Esse extraordinário não a separa porque toda a pessoa é chamada a fazer coisas extraordinárias (MOUNIER, 1974, p. 98-99; grifo do autor).

Para Mounier, a pessoa, essencialmente, não é excepcional. É singular, ou seja, cada pessoa é única, não há uma pessoa igual a outra, mas isso não implica ser excepcional. A vida pessoal não se caracteriza pela exceção, por elevar-se a níveis e alturas que a maioria não alcança, por uma grandeza ou por um heroísmo associados a uma elite, a uma minoria de "grandes homens". Mas, ao mesmo tempo, é chamada a fazer o extraordinário, ou seja, o que é fora do comum, e isso na própria vida cotidiana, comum.

O comum pode ser, por exemplo, trabalhar, estudar etc. O fora do comum pode significar dar um sentido último ao trabalho, ao estudo que não seja, por exemplo, tão somente o econômico. O extraordinário, portanto, está além da dimensão material. Trata-se do transcendente. Mas não um transcendente que se coloca como possibilidade distante da pessoa; antes, pode e mesmo deve realizar-se no cotidiano, na vida comum. Assim, se "toda pessoa é chamada a fazer coisas extraordinárias", esse extraordinário - o que extrapola o ordinário, o habitual, o costumeiro, o medíocre, o vulgar 
- acontece na vida ordinária, comum, cotidiana - do trabalho e do estudo, por exemplo. Nesse caso, fazer o extraordinário não torna a pessoa excepcional, partícipe de uma minoria privilegiada com dons especiais ou de uma casta superior. A propósito, Mounier (1974, p. 99) cita Kierkegaard: "O homem verdadeiramente fora do comum é o homem verdadeiramente comum" - o que talvez sugira que não é tão simples assim ser comum, na medida em que cada pessoa deve (é chamada a) realizar sua singularidade num meio comum, isto é, em meio a outras pessoas singulares.

Mounier afirma a singularidade da pessoa, sem, ao mesmo tempo, tomá-la na pauta da diferença, ou seja, da excepcionalidade, do privilégio: o personalismo não é uma ética dos "grandes homens", e não se dispõe a selecionar; antes, situa a singularidade no que é comum - e, daí, na comunidade. Isso implica que o amadurecer da pessoa, ou seja, o seu desenvolvimento, é um processo que se dá no dia a dia, é um processo comum. Amadurecer, afinal, é o que se espera de todo ser humano, mas cada um deve fazê-lo como pessoa singular que é, ou está chamada a ser - o que é ou pode ser extraordinário num mundo em que predomina a tentação de nele (re)cair, de a ele reduzir-se, ordinariamente.

Contudo, ao mesmo tempo em que relaciona a pessoa ao comum, Mounier (1974, p. 127) sustenta que o ato supremo da pessoa consiste em "ir do sacrifício ao heroísmo":

Não confundamos este ultrapassar do próprio ser com a agitação do ímpeto vital: o ímpeto vital mais não nos leva do que a ele próprio; é paixão pela vida a qualquer preço, mesmo ao preço dos valores que lhe dariam sentido. Aceitar o sofrimento e a morte para não trair a condição humana - ir do sacrifício ao heroísmo - é, pelo contrário, o ato supremo da pessoa. Começa, como escreve Gabriel Marcel no momento em que assumo consciência de que "sou mais do que minha vida". Este é o seu paradoxo: não se encontra (no plano pessoal) senão quando se perde (no plano biológico) (MOUNIER, 1974, p. 127). 
Ao tratar do ímpeto vital, Mounier pode estar se referindo ao elã vital ${ }^{5}$ - um impulso original de criação, do qual provém a vida e sugerindo que tal impulso não conduz a mais nada além dele próprio. Isso pode significar um certo apego à vida, a ânsia de protegê-la a qualquer custo, colocando-a acima até dos valores que dão sentido a ela.

O filósofo defende que o sofrimento e a morte fazem parte da condição humana: por mais que a pessoa queira preservar a vida, conservando o ímpeto vital, é sua condição, como ser humano, sofrer e morrer. Todavia, aponta Mounier, o sofrimento e a morte, paradoxalmente, dão sentido à vida. $\mathrm{O}$ ato supremo da pessoa, então, consiste em aceitar a condição humana. Ele está acima de todos os outros atos, inclusive o do apego à vida. É o ato máximo, implicando o sacrifício da própria vida em favor de valores que valem mais que a vida. Para Mounier (1974), há na pessoa uma indomável paixão que nela arde como fogo divino. É o momento em que a pessoa se vê ameaçada, por exemplo, de servidão, e prefere defender-se mais que à própria vida, o que pode implicar o sacrifício da vida em favor do que vale mais que a vida - a dignidade, por exemplo.

Mounier expõe tal pensamento ao tratar da transcendência - que, nesse contexto, significa ultrapassagem. Ir "do sacrifício ao heroísmo" é um ultrapassar, um ir além de, na medida em que o sacrifício se dá no plano biológico, na vida em sua dimensão biológica, enquanto o heroísmo pode estar no plano pessoal. O filósofo recorre a Nietzsche ${ }^{6}$, nesse passo, para reforçar a ideia de que os que não a poupam a vida, e mesmo procuram não conservá-la, submetendo-se aos sacrifícios que ela exige, são os que

\footnotetext{
5 “A expressão francesa élan vital (em português, elã vital) é utilizada pelo filósofo francês Henri Bergson para designar um impulso original de criação de onde provém a vida e que, no desenrolar do processo evolutivo, inventa formas de complexidade crescente até chegar, no animal, ao instinto e, no homem, à intuição, que é o próprio instinto tomando consciência de si mesmo e de seu devir criador" (JAPIASSÚ, 2008).

${ }^{6}$ Sem citar obra específica, Mounier (1974, p. 127) recorre ao pensamento de Nietzsche quando escreve: "Gosto, diz Nietzsche, das pessoas que se não pretendem conservar, e é com todo o meu coração que amo os que sossobram (sic), porque passaram para o outro lado". Vale ressaltar que Mounier foi duro crítico de Nietzsche (sobretudo, enfrentando as críticas deste ao Cristianismo). Contudo, praticava um movimento de profunda reflexão sobre o pensamento de outros filósofos e não hesitava em recorrer a tais pensamentos quando esses contribuíam para o que se pode chamar de assimilação criativa.
} 
conseguem transpor o plano biológico para atingir o "outro lado" - o do universo pessoal -, manifestando e/ou cumprindo assim, como pessoa, sua transcendência.

Nesse sentido, é possível retomar a ideia de protagonismo, considerando que ele ocorre quando a pessoa escolhe se sacrificar de alguma forma para poder se desenvolver. Muitas das escolhas feitas pela pessoa exigem sacrifícios, envolvendo não raramente o plano biológico: por exemplo, a pessoa pode renunciar a um momento a mais de descanso do corpo para se dedicar um pouco mais aos estudos ou para aprender algo novo e/ou diferente para ela, até então. O movimento de ultrapassagem que caracteriza a transcendência consistiria, nesse caso, em compreender que tais sacrifícios no plano biológico não são em vão, pois podem contribuir para o seu pleno desenvolvimento. A paixão pela própria vida é que se configuraria como um obstáculo ao desenvolvimento da pessoa na medida em que não envolve sacrifícios, sugerindo antes certo comodismo e passividade.

Trata-se, portanto, de um movimento que, não sendo passional, é radicalmente pessoal, isto é, envolve e compromete a pessoa toda:

Edificar é sacrificar. E a decisão não é um ato de força interior, cego e arbitrário. É a pessoa inteira a seu próprio futuro vinculada, concentrada num ato duro e rico, que resume a sua experiência e lhe insere uma outra, nova. As recusas que vamos opondo são reais renúncias, que custam e que por vezes são cruéis, mas não são mutilações. Partem de uma plenitude exigente, e não de uma indigência (MOUNIER, 1974, p. 106).

Nota-se que a palavra "edificar" está relacionada com "sacrificar". Edificar, nesse contexto, pode significar construir, inclusive num sentido de ascensão. Mounier usa, certamente, essa palavra para dizer de um crescimento, o que remete à ideia de desenvolvimento. Esse está vinculado ao sacrifício, ou seja, aos esforços que a pessoa precisa realizar. Parece 
indicar, desse modo, que escolher, por si só, já é um sacrifício, pois envolve decisão. A palavra decisão remete à noção de corte, cisão, o que significa que, ao escolher alguma coisa, a pessoa abre mão de outra(s), a elas renuncia de antemão.

A decisão, afirma Mounier, não deve se configurar como ato cego e arbitrário, em suma, passional. E, se a decisão "é a pessoa inteira ao seu futuro vinculada", ela envolve tudo o que a pessoa é até o presente momento, por suas escolhas e decisões, mas já comprometida com o que ela poderá vir a ser ainda. Daí a ideia de decisão, desse ponto de vista, não como expressão de uma vontade aleatória, caprichosa e/ou inconsciente, mas como ato duro (envolvendo sacrifícios) e, ao mesmo tempo rico, que acrescenta e contribui para o desenvolvimento da pessoa.

O filósofo associa o sacrificar a reais renúncias, que custam e, por vezes, são cruéis, ou seja, duras, mas não implicam mutilações; antes, "partem de uma plenitude exigente". Sacrificar não implica cortes, em que há ausência de regeneração, impossibilitando o desenvolvimento; pelo contrário, Mounier fala em novas experiências - realizadas, certamente, a partir dos sacrifícios. A "plenitude exigente" pode significar que aquilo que a pessoa pode vir a ser depende, necessária e essencialmente, de seus sacrifícios.

Em todas essas reflexões prevalece a instância da escolha: a pessoa escolhe se sacrificar para se desenvolver ou não. Pode-se tomar a ideia de protagonismo como implícita no ato supremo, na medida em que é a pessoa que, como protagonista, decide realizá-lo ou não.

Cabe, por outro lado, pensar esse protagonismo em relação ao que Mounier chama de "vida em poesia":

O excesso da vida de trabalho impede-nos, muitas vezes, de ver que a vida em poesia é aspecto central da vida pessoal e devia contar para o nosso pão cotidiano. Transcendente, "sublime", no sentido autêntico da palavra, não se reduz nem à gulodice das sensações nem à embriaguez da vida; mas, incorporada, também 
não se reduz à pura contemplação da ideia, ou ao poder elaborador do espírito. É, em toda a extensão da existência, a expressão sensível da íntima gratuitidade da existência: compraz-se em desconcertar visões habituais, em lançar sobre os objetos familiares um raio de luz divina, em introduzir nas regiões sublimes a comovente presença de uma percepção familiar. Tal como a ciência das ondas, leva-nos para perto do que nossos sentidos e nossos pensamentos diretamente não captam, tende a tornar-nos presente o infernal e o sobre-humano (MOUNIER, 1974, p. 142-143).

A "vida em poesia" tem a ver com o que o filósofo chama de "sublime" - elemento que não está no plano material e pode ser compreendido como transcendente, elevado, não se reduzindo a sensações nem à contemplação, tampouco ao poder elaborador do espírito. Em outras palavras, não se resume ao sentir e ao contemplar, antes, atinge toda a extensão da existência como uma "expressão sensível de gratuitidade" - é a expressão do que é espontâneo, livre, natural. Essa expressão destina-se a desconcertar "visões habituais" e a lançar luz sobre "objetos familiares" que remetem ao que faz parte do dia a dia, ao costumeiro -, projetando o extraordinário no cotidiano.

Mounier chama a atenção para a importância da experiência estética na vida cotidiana da pessoa. Assim, não se trata apenas de sentir e contemplar, mas de colocar em prática, visto que existe a possibilidade de uma experiência que pode se dar no cotidiano.

Em contraposição à "vida em poesia", há a "vida de trabalho", uma dimensão que faz parte do plano material da pessoa, assim como do seu dia a dia. Conforme Mounier, "o excesso da vida de trabalho" é a causa de não nos voltarmos para "a vida em poesia". Em outras palavras, a pessoa pode estar se ocupando demasiadamente da vida de trabalho, deixando de lado a experiência estética: o que o filósofo quer mostrar, no fundo, é que o trabalho não é o valor primeiro do homem, porque ele não é toda sua 
atividade, nem sua atividade essencial como pessoa; a "vida em poesia" é superior em dignidade espiritual.

Mounier afirma que a "vida em poesia" é aspecto central da vida pessoal e, por conseguinte, pode estar no centro do desenvolvimento da pessoa. Ela "deve contar para o nosso pão quotidiano", isto é, para o que faz parte do dia a dia da pessoa - incluindo, sem dúvida, suas ações e escolhas. Deveria, portanto, ser algo comum: assim como se come o pão para alimentar o corpo, dimensão física da pessoa, dever-se-ia viver "em poesia", vivenciar diariamente a experiência estética como dimensão essencial do universo pessoal. Pode-se retomar, de certa forma, a ideia do extraordinário no centro da vida comum - a capacidade de integrar a experiência estética ao dia a dia. Se tal experiência é essencial ao desenvolvimento da pessoa, cabe - e resta - a ela, no processo de amadurecer livremente, escolher e decidir incorporá-la em sua vida, como seu "pão quotidiano".

Isso não significa, evidentemente, que Mounier abstraia a pessoa de suas condições materiais de existência. Se, de um lado expõe aspectos que se referem à dimensão transcendente (o sublime, o extraordinário), por outro, considera a pessoa também em seus papéis de trabalhador, cidadão, pai de família etc.

Ele defende que o Estado e a sociedade civil devem assegurar às pessoas padrões de dignidade, no que se refere à alimentação, à habitação, à educação, à saúde, ao trabalho, ao ambiente. A pessoa, dessa forma, é a que trabalha, recebe salário, se alimenta, frequenta a escola, tem direitos e deveres, integra entidades, associações, organizações - elementos e relações que dizem respeito às suas dimensões política, econômica e social.

O que filósofo critica, considerando o contexto da época, é o fato de tais categorias (sobretudo, o cidadão e o trabalhador) terem primazia em relação à pessoa. Mounier afirma que a pessoa não é o cidadão, tendo em vista que o segundo entende-se inserido nas esferas jurídicas do Estado, ao passo que a pessoa transcende tais esferas. Mounier não exclui da pessoa os aspectos que a caracterizam como cidadã - os direitos e deveres, a inserção 
na vida política, econômica e social - porém deixa claro que a pessoa não se resume em tais aspectos.

Da mesma forma, Mounier não descura das condições econômicas:

Para a pessoa é necessidade elementar o dispor de um certo número de objetos com os quais, um pouco como acontece com outras pessoas, se vá familiarizando com o correr do tempo e o hábito. Afirmar-se é, antes de mais nada, ter espaço. É, pois, preciso que não oponhamos demasiadamente o ter e o ser, como duas atitudes existenciais entre as quais fosse preciso escolher. Pensemos, antes, em dois polos, no meio dos quais a existência está compreendida. Não é possível ser sem ter, embora nosso ser seja infinita capacidade de ter, não seja nunca esgotável pelo que tem e o ultrapasse em muito pelo seu significado. Sem ter, a existência não se agarra, perde-se nos objetos. Para mais, possuir é entrar em contato, renunciar à solidão, à passividade; há falsas pobrezas que mais não são do que escapatórias (MOUNIER, 1974, p. 89; grifos do autor).

O fato de a pessoa possuir objetos de uso cotidiano como roupas, sapatos, livros, móveis etc., é uma questão de necessidade básica, algo comum. Além disso, afirmar-se como pessoa é ter espaço - por exemplo, uma casa, onde estão dispostos os objetos pessoais. Na concepção de Mounier, o ter não se opõe ao ser. Não se trata, portanto, de contrapor nem de escolher entre o que a pessoa é e o que a pessoa tem, na medida mesma em que o que está em jogo são necessidades básicas da pessoa, tais como morar, se alimentar, se vestir etc. Por isso, mesmo afirmando que a pessoa não se limita ao que possui, ou seja, seu significado não se resume aos bens materiais, Mounier diz que não é possível ser (pessoa) sem ter, justamente porque o ter pode garantir o ser. Trata-se de um ter concreto, que traduz necessidades da pessoa histórica, social e politicamente situada (no aqui-eagora).

Filos. e Educ., Campinas, SP, v.12, n.2, p.1032-1054, maio/ago. 2020 - ISSN 1984-9605 
Se Mounier critica o ter, é também pelo fato de se tomar essa dimensão material como valor central para o desenvolvimento da pessoa, o que significaria considerá-la tão somente por suas posses:

Há no centro de toda a possessão humana uma alienação do trabalho sempre renovada. Como a mão do rei Midas, a minha posse tende à degradação dos seres e objetos de que me aproprio; apresentando-me face a eles como conquistador que exige ou dono que submete, vou bloqueando simultaneamente a disponibilidade deles e a minha. Fala-se muitas vezes do "desenvolvimento da pessoa", como se para aumentarmos o nosso valor fosse preciso aumentar as nossas posses. (MOUNIER, 1974, p. 90-91).

É nesse contexto que cabe interpretar o que Mounier entende por "vida de trabalho". Mais especificamente, o trabalho enquadra-se na teoria da ação do filósofo, que pode ser considerada o centro de sua filosofia personalista, uma vez que tudo quanto ele pôde apreender da realidade foi em prol do comprometimento contra a "desordem estabelecida" pela sociedade individualista, que impossibilita o homem de ser pessoa: "É a ação que modifica a realidade exterior, forma os homens, aproxima-os uns dos outros e enriquece o seu universo de valores" (MOUNIER, 1974, p. $155)$.

São quatro as condições que devem estar presentes nas ações do homem, conferindo sentidos aos fins que pretendem alcançar:

1. No fazer (poiein) a ação tem por principal fim dominar e organizar uma matéria exterior. Chamá-la-emos econômica: a ação do homem sobre as coisas, ação do homem sobre o homem no plano das forças naturais ou produtivas, está presente sempre que o homem, até mesmo em problemas de cultura ou religião, desmonta, ilumina ou engrena determinismos. [...] 
2. Vista sob o ângulo do agir (prassein) a ação não tem como principal fim a construção de uma obra exterior, mas a formação daquele que a executa, a sua capacidade, as suas virtudes, a sua unidade pessoal. [...]

3. Teorein, diziam os gregos para designar este aspecto da nossa atividade que explora os valores e se enriquece à medida que se estende o seu reino sobre a humanidade. Se conservarmos a tradução clássica de ação contemplativa temos, contudo, que apreciar que essa contemplação para nós não depende somente da inteligência, mas do homem inteiro, não é evasão da atividade comum para uma atividade escolhida e separada, mas aspiração a um reino de valores que abranja e desenvolva toda a atividade humana. [...]

4. [...] dimensão coletiva da ação. Comunidade de trabalho, comunidade de destino ou comunhão espiritual são indispensáveis à sua humanização integral. [...] (MOUNIER, 1974. p. 155; grifos do autor).

Verifica-se que o trabalho faz parte de uma realidade mais ampla, que compreende o fazer e o agir humanos em suas distintas dimensões. Quando Mounier atribui à ação a virtude de modificar a "realidade exterior", indica que o trabalho não deve ser considerado por si só, sob o risco de se reduzir a determinismos. Antes, deve ser modificado por aquilo que possa dar a ele um novo significado - por exemplo, a fraternidade que pode existir entre os camaradas de trabalho. Isso significa que a pessoa pode modificar sua "realidade exterior" (a sociedade e suas instituições), incluindo a "vida de trabalho". Essa possibilidade e a capacidade correspondente supõem e implicam um protagonismo, que se dá no âmbito socioeconômico da vida cotidiana, dimensão material da pessoa.

Se de um lado, Mounier diz dos aspectos transcendentes da pessoa, de outro, põe em evidência os aspectos econômico, social e político, que também devem ser levados em conta no desenvolvimento da pessoa, mostrando que, além das escolhas, a pessoa pode ser influenciada por sua ambiência histórica (a economia, a política, a família, a educação, a cultura, 
o meio ambiente, a sociedade de modo geral etc.), pois faz parte de uma realidade concreta. Sua existência é enraizada na história.

No centro dessas reflexões permanece ainda a questão da escolha e, por conseguinte, do protagonismo da pessoa. A pessoa pode ser o que recebe do mundo, mas suas escolhas permitem que não se limite a reducionismos; assim, ela é também o que faz. Esse movimento constante, que envolve a livre escolha dos valores morais, éticos, estéticos, bem como os políticos, sociais e econômicos, garante à pessoa amadurecer livremente. Cada pessoa pode escolher aceitar ou recusar, é livre para escolher os valores que podem contribuir para o seu desenvolvimento. De tal perspectiva, amadurecer é um processo de autodesenvolvimento, o que significa que cabe a cada pessoa, no fim das contas, desenvolver-se.

Pode-se considerar, então, que a educação, no personalismo mounieriano, é também autoeducação. A educação, em sua acepção mais ampla, pode oferecer condições para o despertar da pessoa, criando oportunidades para que a mesma possa realizar escolhas, mas uma vez desperta, a pessoa é a principal responsável por sua própria educação. Daí a ideia de que a pessoa não só receba e assimile conhecimento, mas participe do processo de educação através de suas escolhas, num movimento livre e criativo. Portanto, a educação da pessoa, em Mounier, depende muito mais dela do que de outros (Estado, família, igreja, sociedade etc.), implicando um esforço que envolve os sacrifícios que ela está disposta a enfrentar para se autodesenvolver.

Autoeducação e autodesenvolvimento, em Mounier, podem ser compreendidos, ainda, como processos contínuos, assim como o próprio amadurecer, cujo significado nada tem a ver com a noção de um amadurecimento "natural", como o do fruto que amadurece durante um período específico, após o qual começa a apodrecer. Amadurecer, no personalismo, é um processo contínuo, implicando a pessoa ser e viver como tal. Não se trata de atingir uma determinada fase da vida, mas de um movimento que envolve diferentes aspectos da vida e que Mounier define como uma "permanência aberta", ou seja, que está sempre por se completar. 
Dessa forma, deve-se entender a plenitude como um movimento de se completar, que se dá conforme a pessoa realiza escolhas que possibilitem a personalização; ela não é o todo acabado, mas se dá em cada ato de personalização, em cada movimento que o homem realiza para ser pessoa. Como, para o personalismo mounieriano, a pessoa não nasce perfeita e acabada, o processo de amadurecer inicia-se com seu nascimento, só terminando quando de sua morte. Do mesmo modo, então, a autoeducação é um processo que dura toda a vida, visto que depende da pessoa e essa está ou pode estar, segundo suas escolhas - em constante processo de amadurecimento.

A educação para o pleno desenvolvimento da pessoa, é, então, um processo que começa com o despertar do homem para a personalização. Tal movimento não se dá de uma só vez, mas se realiza conforme a pessoa faz suas escolhas, assim como a plenitude não se realiza como um todo acabado, mas como um movimento, um vir a ser.

\section{Considerações finais}

O personalismo de Emmanuel Mounier rejeita a ideia de uma educação voltada para preparar a pessoa apenas para exercer uma função social. A isso Mounier chama "fazer", "moldar"; em contrapartida, defende o despertar pessoas e o seu livre amadurecer como finalidades da educação. Isso porque, na visão do filósofo, a pessoa não é apenas o cidadão e o trabalhador, nem os aspectos de sua vida restringem-se somente aos socioeconômicos.

Mounier considera a pessoa em sua singularidade e combate a ideia de que a mesma seja tratada como objeto, coisa padronizada e uniformizada. De acordo com sua filosofia, trata-se de considerar que a pessoa, sendo livre, tem possibilidade de protagonizar sua própria educação e seu próprio desenvolvimento. Tais processos, portanto, do ponto de vista de Mounier, dependem muito mais da própria pessoa que de outros agentes (Estado, escola, família, sociedade etc.). 
A pessoa, para Mounier, não está obrigada a se considerar apenas em sua dimensão socioeconômica, porque ela é livre. E é nesse movimento de liberdade que o homem pode escolher se desenvolver como pessoa despertar, amadurecer e ser pessoa. No fundo, a educação, para Mounier, é também autoeducação e, por conseguinte, o desenvolvimento é igualmente autodesenvolvimento; ambos dizem respeito ao protagonismo da pessoa. Esses processos exigem, mesmo na dinâmica da liberdade, autodisciplina: os sacrifícios que o homem deve empreender para o seu desenvolvimento como pessoa.

\section{Referências}

JAPIASSÚ, Hilton; MARCONDES, Danilo. Dicionário Básico de Filosofia. $5^{\text {a }}$ ed. Rio de Janeiro: Zahar, 2008. Disponível em: $<$ https://sites.google.com/view/sbgdicionariodefilosofia/el $\%$ C3\%A3-vital>. Acesso em: 12 de set. 2019.

LORENZON, Alino. Atualidade do pensamento de Emmanuel Mounier. $2^{\mathrm{a}}$ ed. Ijuí, RS: Unijuí, 1996.

MOIX, Candide. O pensamento de Emmanuel Mounier. Rio de Janeiro: Paz e Terra, 1968.

MOUNIER, Emmanuel. O personalismo. Trad. João Bénard da Costa. $3^{\mathrm{a}}$ ed. Santos, SP: Martins Fontes, 1974.

Le Personnalisme. Paris: Les Presses Universitaires de France,

1971. Col. Que sais-je?

. Tratado del Caracter. Buenos Aires, Argentina: Antônio Zanora,

1971. Col. El mundo y el hombre.

PEIXOTO, Adão José. Pessoa, existência e educação. Goiânia: Ed. da UCG, Ed. Alínea, 2009.

; VON ZUBEN, Newton Aquiles; GOTO, Tommy Akira (orgs.).

A pessoa: da conceituação à afirmação da dignidade humana. Curitiba: CRV, 2017.

REBOUL, Oliver. Filosofia da Educação. Trad. Luiz e J.B. Damasco Penna. São Paulo: Companhia Editora Nacional, 1998.

SEVERINO, Antônio Joaquim. Antropologia personalista de Emmanuel Mounier. São Paulo: Saraiva, 1974.

Filos. e Educ., Campinas, SP, v.12, n.2, p.1032-1054, maio/ago. 2020 - ISSN 1984-9605 
SILVA, Patrícia Costa e. Racionalidade técnica e formação: um estudo a partir do personalismo de Mounier. 2015. 190 f. Tese (Doutorado em Educação) - Faculdade de Educação, Universidade Federal de Goiás, Goiânia.

Submetido em: $25 / 02 / 2020$

Aceito em: $23 / 06 / 2020$

Publicado em: 30/08/2020 